\title{
Pleural effusion after rupture of silicone bag mammary prosthesis
}

\author{
WENDY M R STEVENS, JONATHAN G W BURDON, JOHN F NIALL
}

From St Vincent's Hospital, Melbourne, Australia

Augmentation mammoplasty with implantation of silicone bag prostheses is commonly performed for cosmetic reasons. Despite its popularity it is associated with various complications. We describe a case of pleural effusion following the rupture of a prosthetic silicone bag, a complication that has not previously been reported.

\section{Case report}

A 31 year old woman was admitted to hospital with a two week history of left sided pleuritic chest pain, which came on 24 hours after she had sustained a blow of moderate severity on the left anterior chest wall. She subsequently developed breathlessness on moderate exertion. There was no associated cough, sputum production, or fever. Five years previously she had had bilateral augmentation mammoplasties with insertion of silicone bag prostheses for cosmetic purposes.

Examination at the time of admission showed a fit looking young woman. She was normotensive with a pulse rate of 80 beats $\mathrm{min}$ and a respiratory rate of $16 / \mathrm{min}$. Physical examination revealed signs of a large left pleural effusion but no other abnormalities. In particular, the cardiovascular system was normal and there was no lymphadenopathy or hepatosplenomegaly. Both breasts were soft and appeared equal in size. A chest radiograph confirmed the presence of a large left pleural effusion but was otherwise normal. Computed tomography of the thorax confirmed the radiological findings. Full blood examination was normal and the erythrocyte sedimentation rate was $25 \mathrm{~mm}$ in one hour. Concentrations of plasma urea and electrolytes and of serum calcium and phosphate and the results of liver function tests were normal and antinuclear antibody and rheumatoid factor tests gave negative results. Routine flexible bronchoscopy showed normal bronchial anatomy. Bronchial washings and brushings yielded no abnormal cytological or microbiological findings and no acid fast bacilli.

Pleural aspiration yielded slightly turbid, straw coloured fluid with a protein concentration of $46 \mathrm{~g} / \mathrm{l}$, glucose $5 \cdot 3$ $\mathrm{mmol} / \mathrm{l}$, and lactic dehydrogenase activity 372 IU/l. Microscopy showed a moderate number of polymorphs and numerous lymphocytes. No malignant cells were seen. A

Address for reprint requests: Dr Jonathan G W Burdon, Respiratory Function Laboratory, St Vincent's Hospital, Fitzroy, Australia 3065.
Gram stain and stains for acid fast bacilli were negative and cultures yielded no growth.

Subsequently a percutaneous pleural needle biopsy (Abrahm's needle) was performed and the chest was aspirated to dryness. The biopsy showed a thickened pleura with a dense mixed cellular infiltrate of lymphocytes, plasma cells, and occasional eosinophils and foamy macrophages. Several granulomas with large multinucleate giant cells suggestive of a foreign body reaction were seen. Stains for acid fast bacilli and fungi were negative. Two litres of pleural fluid were aspirated after the pleural biopsy. An oily layer (thin film) was observed on the top of the fluid, consistent with the presence of silicone gel in the aspirate.

After the complete aspiration the patient's symptoms resolved. When reviewed three months later she was symptom free and there had been no recurrence of the effusion.

\section{Discussion}

The diagnosis of a pleural reaction to silicone with a resultant effusion was based on the clinical history, the histological findings of a foreign body reaction in the pleura, and the presence of a substance in the aspirate consistent with free silicone. We suspect that at the time of the trauma to the chest wall rupture of the left breast prosthesis occurred and a jet of silicone was forced under high pressure into the left pleural cavity, where a foreign body inflammatory reaction developed and resulted in a pleural effusion.

Silicone has been used for many years in cosmetic surgery. When first introduced it was thought to be relatively inert and to cause minimal tissue reaction. There have, however, been several reports of foreign body reactions occurring in response to the presence of silicone, both in animal experiments $^{12}$ and in clinical practice. ${ }^{3-6}$ The histological features reported in these cases are similar to those seen in our case, the predominant finding being a mixed cellular infiltrate of histiocytes, lymphocytes, eosinophils, and multinuclear giant cell granulomas. Macrophages with foamy cytoplasm have also been reported.

Rupture of silicone breast prostheses is a well recognised occurrence, most frequently occurring at the time of insertion or during manual compression for closed capsulotomy. ${ }^{6-8}$ There have been reports of rupture after chest wall trauma. ${ }^{9}$ Migration of the gel after rupture to the abdominal wall, ${ }^{3}$ axilla, ${ }^{4}$ groins, ${ }^{3}$ and upper arm $^{5}$ has also been reported, resulting in a foreign body inflammatory response at the site of the free silicone. To our knowledge there are no previous reports of pleural effusions occurring as a result of ruptured breast prostheses. With the increasing use of these devices in cosmetic surgery, however, we suspect that more cases will occur. 
Treatment of our patient was accomplished by complete aspiration of the effusion. Presumably we were able to remove most of the free silicone with this procedure, thus removing the stimulus for the inflammatory reaction. We assume that the small amount of silicone in any residual fluid was removed by the lymphatic system, as has occurred in other cases. ${ }^{10}$

\section{References}

1 Brody GL, Frey CF. Peritoneal response to silicone fluid. Arch Surg 1968;96:237-41.

2 Vistnes LM, Bentley JW, Fogarty DC. Experimental study of tissue response to ruptured gel-filled mammary protheses. Plast Reconstr Surg 1977;59:31-4.

3 Delage C, Shane JJ, Johnson FB. Mammary silicone granuloma. Arch Dermatol 1973;108:104-7.
4 Wintsch W, Smahel J, Clodius L. Local and regional lymph node $\overrightarrow{\overline{\vec{N}}}$ response to ruptured gel-filled mammary protheses. Br J Plast Surg 1978;31:349-52.

5 Mason J, Apisarnthanarax P. Migratory silicone granuloma. Arch Dermatol 1981;117:366-7.

6 Eisenberg HV, Bartels RJ. Rupture of a silicone bag-gel breast $\overparen{\mathbb{D}}$ implant by closed compression capsulotomy. Plast Reconstr Surg 1977;59:849-50.

7 Nelson GD. Complications of closed compression after augmentation mammoplasty. Plast Reconstr Surg 1980;66:71-3.

8 Laughlin RA, Raynor AC, Habal MB. Complications of closed $\vec{\overrightarrow{ }}$ capsulotomies after augmentation mammaplasty. Plast Reconstr Surg 1977;60:362-3.

9 Dellon AL, Cowley RA, Hoopes JE. Blunt chest trauma: evalu- $\vec{x}$ ation of the augmented breast. J Trauma 1985;20:982-5.

10 Hausner RJ, Schoen FJ, Pierson KK. Foreign body reaction to silicone gel in axillary lymph nodes after an augmentation $\vec{\circ}$ mammoplasty. Plast Reconstr Surg 1978;62:381-4. 